\title{
Automated measurement of changes in feeding behavior of milk-fed calves associated with illness
}

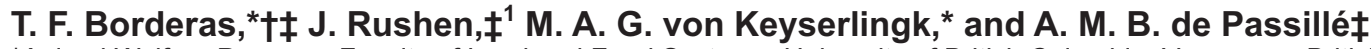 \\ *Animal Welfare Program, Faculty of Land and Food Systems, University of British Columbia, Vancouver, British Columbia, V6T 1Z4, Canada \\ †Departamento de Producción Agrícola y Animal, Universidad Autónoma Metropolitana-Xochimilco, Coyoacán, México \\ $\ddagger$ Pacific Agri-Food Research Centre, Agriculture and Agri-Food Canada, PO Box 1000, Agassiz, British Columbia, V0M 1A0, Canada
}

\section{ABSTRACT}

There is a need for improved methods of detecting illness among group-housed milk-fed calves. In 4 separate experiments, we examined whether illness in group-housed dairy calves fed with an automated milk feeder changed their feeding behavior, and whether these changes were affected by low $(\mathrm{n}=26)$ or high $(\mathrm{n}$ $=38$ ) milk rations. All calves were subjected to regular health checks that included general condition, rectal temperature, lung auscultation, and fecal scoring. We match paired calves that succumbed to illness with healthy calves on the same feeding allowance. In the days following clinically identified illness (gastroenteric or respiratory affections), sick calves fed high allowances of milk or milk replacer decreased milk intake $(-2.59 \pm 0.7 \mathrm{~L} / \mathrm{d})$ and frequency of visits to the milk feeder $(-2.43 \pm 0.3$ visits $/ \mathrm{d})$, and increased the duration of each visit to the milk feeder $(1.66 \pm 0.5 \mathrm{~min} /$ visit) compared with healthy calves fed at the same allowance. However, sick calves fed a low allowance of milk or milk replacer only decreased the duration of each visit to the milk feeder $(-1.35 \pm 0.2 \mathrm{~min} /$ visit $)$ compared with healthy calves. Feed allowance affected feeding behavior associated with illness of milk fed calves.

Key words: calf, feeding behavior, health, automatic milk feeder

\section{INTRODUCTION}

The use of automated feeders has facilitated grouphousing of milk-fed calves because of increased labor efficiency (Kung et al., 1997; Bøe and Færevik, 2003; Hepola, 2003). However, concern remains that detection of illness is more difficult (Svensson and Jensen, 2007). Therefore, there is a need for tools that identify sick calves or those at risk for disease.

Received February 6, 2009.

Accepted May 18, 2009.

${ }^{1}$ Corresponding author: rushenj@agr.gc.ca
One response to disease is reduced feed intake (Johnson, 2002) and this is often the first sign that an animal is ill. Measures of feeding behavior may, therefore, be useful in detecting illness. Changes in feeding behavior preceding illness of animals fed with automated feeders have been reported in dairy cows (Urton et al., 2005; Huzzey et al., 2007; Lukas et al., 2008) and beef cattle (Sowell et al., 1998; Quimby et al., 2001). In calves, Maatje et al. (1993) and Svensson and Jensen (2007) have reported effects of illness on feeding behavior of calves fed by automated milk feeding systems, but the effects were dependent on levels of milk intake of the calves. In veal calves fed large amounts of milk, Maatje et al. (1993) found that the rate of milk intake and total consumption were the best indicators of disease. In contrast, when calves were fed restricted amounts of milk, Svensson and Jensen (2007) reported that the measures identifying calves at risk for disease were limited to frequency of unrewarded visits to the milk feeder and not on actual milk intake. Borderas et al. (2008) also noted that illness induced by injections of bacterial endotoxin in young milk-fed calves fed restricted amounts of milk decreased time spent eating hay but not milk intake. Therefore, the aim of this study was to assess if changes in feed intake and in the pattern of visits could be detected by automated milk feeding equipment before and during the onset of illness in dairy calves, and whether these changes were affected by the amount of milk or milk replacer provided.

\section{MATERIALS AND METHODS}

The institutional animal care committees (monitored by the Canadian Council for Animal Care) approved all procedures described in this study.

Using data collected from 4 previous experiments (Exp.; Exp. 1 to 4), we examined the feeding behavior of sick and healthy unweaned, group-housed dairy calves up to $21 \mathrm{~d}$ of age fed either low ( $\mathrm{n}=26 ; 12$ males and 14 females) or high $(\mathrm{n}=38 ; 16$ males and 22 females) milk or milk replacer. 
Table 1. Feeding conditions for experiments 1 to 4

\begin{tabular}{lcccc}
\hline Item & Exp. 1 & Exp. 2 & Exp. 3 & Exp. 4 \\
\hline Milk or milk replacer & Milk replacer & Milk & Milk & 12 \\
High milk allowance (L/d) & Ad libitum & 12 & NA $^{2}$ & 12 \\
Low milk allowance (L/d) & 4 & $42^{3}$ & $21.6^{4}$ & 4 \\
Concentrate CP (\%) & Calm; Lely Inc. & Calm; Lely Inc. & CF1000 CS COMBI; & $21.6^{4}$ \\
Feeder brand & & & De Laval Inc. & CF1000 CS COMBI; \\
& & & De Laval Inc. \\
\hline
\end{tabular}

${ }^{1}$ Violac, Coopérative Fédérée de Québec, Montreal, Canada.

${ }^{2} \mathrm{NA}=$ no animals in low milk allowance treatment.

${ }^{3}$ Goliath XLR, Coopérative Agricole des Cantons, Québec, Canada.

${ }^{4}$ Unifeed Ltd., Chilliwack, Canada.

In these experiments, Holstein calves (birth weight $=44.99 \pm 6.04 \mathrm{~kg}$; mean $\pm \mathrm{SD}$ ) were separated from their mother within the first $24 \mathrm{~h}$ of life, weighed, fed at least $4 \mathrm{~L}$ of colostrum in a single meal within $6 \mathrm{~h}$ of birth, and allocated to individual pens, where they were fed $4 \mathrm{~L} / \mathrm{d}$ until 4 or $5 \mathrm{~d}$ of life and then transferred to group pens. In all experiments, calves were always kept at a density of at least $1.4 \mathrm{~m}^{2} /$ head. Group size ranged from 3 to 16 in Exp. 1, from 4 to 13 in Exp. 2, and was fixed at 4 and 5 calves per pen in Exp. 3 and Exp. 4, respectively. In all experiments, the calves were randomly allocated to milk feeding allowances while balancing for birth weight. Table 1 shows the feeding treatments for each experiment. In all experiments, calves were allowed ad libitum access to hay and water. Concentrate was available ad libitum from the first day after moving to the group pens through a feeding bowl at a feeding station adjacent to the automated milk feeder system. For more detailed methods on rearing conditions as well as the growth and performance data please refer to Borderas et al. (2006) for Exp. 1, Borderas et al. (2007) for Exp. 2, and Sweeney (2007) and Sweeney et al. (2008) for Exp. 3. Rearing conditions in Exp. 4 were similar to those in Exp. 3 except for the length of the feeding regime ( $82 \mathrm{vs} .41 \mathrm{~d}$ ).

In Exp. 1, 2, and 4, daily health checks that included rectal temperature, respiratory and cardiac rates and sounds, presence of diarrhea, presence of nasal and ocular discharges, general state of the coat, and dehydration (including tent test and muzzle humidity) were performed daily by a veterinarian. In Exp. 3, calf health was checked daily by the barn staff following a standard operating procedure developed in conjunction with a veterinarian. Of the 28 high-allowance calves, 18 became ill from gastrointestinal illness, 2 from respiratory illness, and 8 from a combination of the two as judged by the veterinarian or by the farm staff. Of the 21 low-allowance calves, 11 became ill from gastrointestinal illness, 7 from respiratory illness, and 3 from a combination of the two. Twenty-two calves became ill before $11 \mathrm{~d}$ of age, whereas the remaining 10 became ill between d 11 and 20. Medical treatment was recorded for every sick calf. Boluses of neomycin and sulfametazine (Neo Sulfa-E, Vetoquinol Inc., Lavaltrie, Canada) were administered to 2 low-allowance calves in Exp. 1 and to 2 high-allowance calves in Exp. 3. A kaolin-pectate suspension (Kaopectate, Pfizer Inc., Kirkland, Canada) was administered to 4 calves in Exp. 1 (2 low-allowance and 2 high-allowance). Rehydrating solutions (Electrolytes Plus, Vetoquinol Inc., in Exp. 1 and Hydrafeed, EXL Laboratories, Minneapolis, MN, in Exp. 2, 3, and 4) were provided to the remaining sick calves. Treatments lasted on average $( \pm \mathrm{SD}) 2.37$ $( \pm 0.8) \mathrm{d}$ with a range of 1 to $4 \mathrm{~d}$.

\section{Statistical Analysis}

Data from calves with 2 or more episodes of illness were eliminated from the analysis. For each sick calf, we identified a healthy calf that was in the same experiment, on the same feed allowance, of the same age, and of similar birth weight (birth weight: mean $\pm \mathrm{SD}$; sick calves: $45.68 \pm 6.2 \mathrm{~kg}$; healthy calves: $44.31 \pm 5.9 \mathrm{~kg}$ ) as its matched pair. Day 0 was assigned as the day on which illness was first detected in the sick calves and the equivalent day for the healthy matched controls. Data collected for each calf (and its matched pair) included average daily milk intake $(\mathrm{kg})$, the total number of daily visits to the milk feeder, and the average duration of visits to the milk feeder. To remove instances where the receiver on the milk feeder briefly lost contact with the transmitter on the calf, a visit to the milk feeder was defined using the frequency distribution of natural log intervals between visits recorded by the milk feeder station following the methods described by von Keyserlingk et al. (2004). Because we had missing data from some animals before illness, we tested the effect of illness on these variables separately for the period before and up to illness detection ( $\mathrm{d}-2$ to 0 ) and after illness detection (d 1 to 7 ). The presence of marked effects of milk 
Table 2. F-value and probability level for the effect of health status, day of sickness, and the interaction of health status and day of sickness on milk intake, total visits to the milk feeder, and duration of the visits to the milk feeder of calves fed high and low allowances of milk

\begin{tabular}{|c|c|c|c|c|c|c|}
\hline \multirow[b]{2}{*}{ Item } & \multicolumn{2}{|c|}{ Health status } & \multicolumn{2}{|c|}{ Day of sickness } & \multicolumn{2}{|c|}{ Health status $\times$ day of sickness } \\
\hline & $F$-value & $P$-value & $F$-value & $P$-value & $F$-value & $P$-value \\
\hline Milk intake & 3.30 & 0.07 & 0.85 & 0.43 & 1.69 & 0.19 \\
\hline Visits to feeder & 5.52 & 0.02 & 3.69 & 0.03 & 0.77 & 0.47 \\
\hline Duration of visits & 3.61 & 0.06 & 0.74 & 0.48 & 0.08 & 0.92 \\
\hline \multicolumn{7}{|l|}{ Low allowance ${ }^{2}$} \\
\hline Visits to feeder & 0.53 & 0.47 & 1.24 & 0.30 & 0.01 & 0.99 \\
\hline Duration of visits & 4.51 & 0.04 & 0.03 & 0.97 & 0.97 & 0.38 \\
\hline \multicolumn{7}{|l|}{ Sick $d 1$ to 7} \\
\hline \multicolumn{7}{|l|}{ High allowance ${ }^{3}$} \\
\hline Milk intake & 12.89 & $<0.001$ & 7.43 & $<0.001$ & 2.15 & 0.04 \\
\hline Visits to feeder & 15.87 & $<0.001$ & 0.11 & 0.99 & 0.28 & 0.94 \\
\hline Duration of visits & 17.06 & $<0.001$ & 0.24 & 0.96 & 0.98 & 0.44 \\
\hline
\end{tabular}

${ }^{1}$ Error $\mathrm{df}=88$.

${ }^{2}$ Error df $=60$.

${ }^{3}$ Error df $=239$.

${ }^{4}$ Error $\mathrm{df}=156$.

feeding allowance on feeding behavior (e.g., Borderas et al., 2006, 2007) resulted in our testing the effects separately for calves fed high or low rations of milk using a repeated-measures mixed model, PROC MIXED of SAS (SAS Institute, 1999). The model included the matched pair of calves as a random component and milk allowance (high or low), health status (sick or matched healthy control), day of sickness ( -2 to 0 or 1 to 7 ), and the interaction of health status and day of sickness as fixed components. To test for differences between experiments, we initially included experiment as a factor and the interaction of experiment with the feeding behavior measures. However, no effect of experiment (or interaction) was noted so this term was removed from subsequent analyses. Where a significant overall effect $(P<0.05)$ or a trend $(P>0.05$ but $<0.10)$ of health status was found, we used least squares means to compare the effect of health status by day. Because a large number of sick calves identified suffered from a combination of gastrointestinal and respiratory diseases and very few showed only respiratory disease, we were unable to test for the effect of different illnesses. In preliminary analyses, we also tested the effects of antimicrobial agents (i.e., neomycin, sulfamethazine), as there is some indication that these agents may affect intake behavior (Merck, 2006). However, results showed no differences in feeding behavior between treated and untreated sick animals and thus the data collected from treated calves were retained.

\section{RESULTS}

The results of the analysis with PROC MIXED are shown in Table 2. Daily milk intake, the frequency of visits to the milk feeder, and the mean duration of visits to the milk feeder for sick and healthy calves at both feed allowances are shown in Figure 1.

Sick calves fed a high allowance of milk showed a reduction in the frequency of visits to the milk feeder, and a trend for reduced milk intake and increased mean duration of visits in the days preceding and on the day that illness was detected ( $\mathrm{d}-2$ to $0 ; P<0.05$ ). There was no interaction between health status and day of sickness. However, differences between sick and healthy calves before the onset of illness in these variables were limited to d 0 (Figure 1). In the days following the detection of illness, sick calves fed a high allowance of milk decreased milk intake, frequency of visits to the feeder, and the duration of visits $(P<0.05$; Table $2)$. We also observed an interaction between health status and day of illness for milk intake $(P<0.05)$. However, daily comparisons indicated differences in the mentioned variables (or nonsignificant trends) between healthy and sick calves only on d 1, 2, and 3 (Figure $1)$.

Sick calves fed low allowances of milk or milk replacer showed no differences in milk intake or frequency of visits to the feeder, either before $(P=0.3$ and $P=0.5$, respectively) or after illness was detected $(P=0.6$ and 

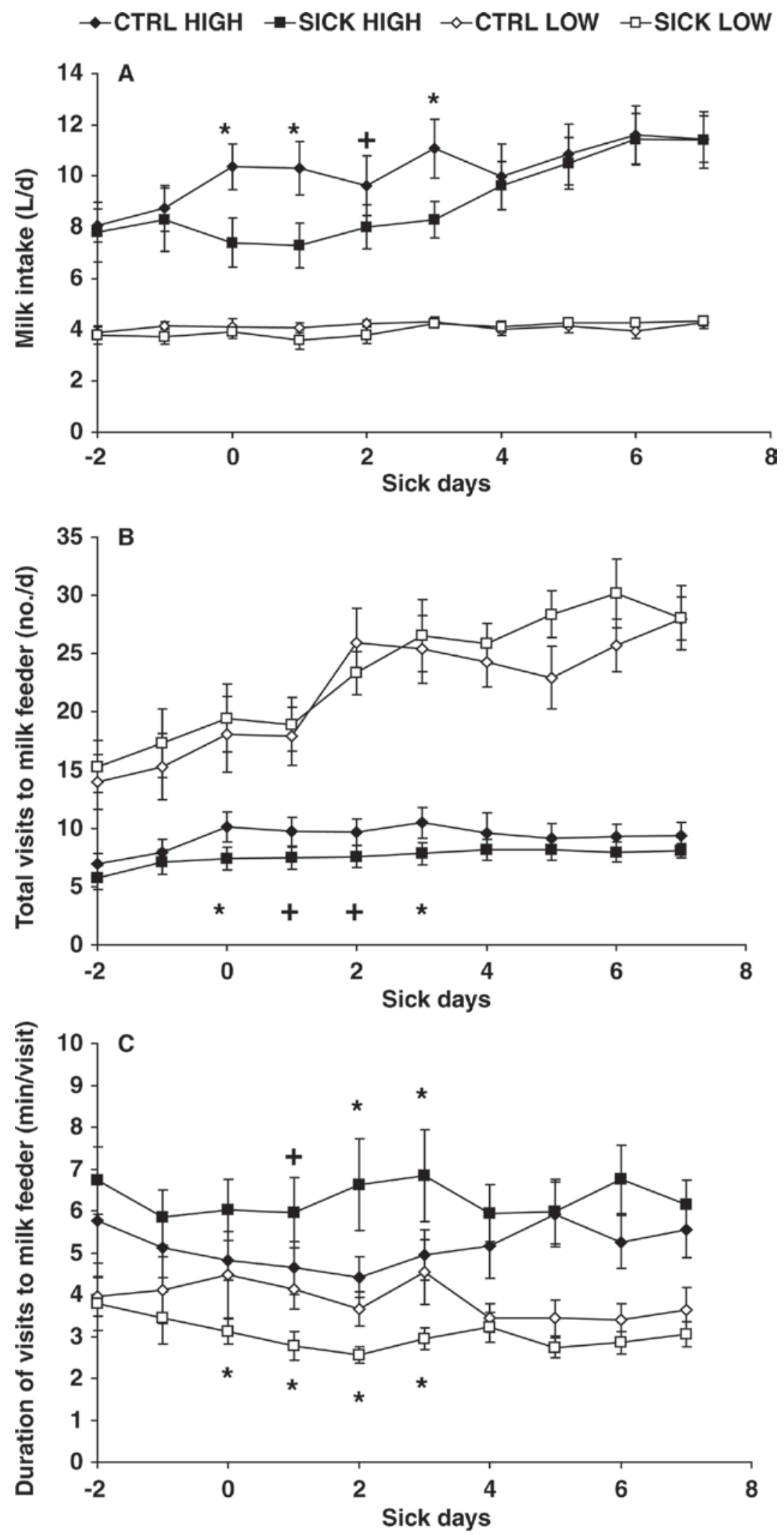

Figure 1. Mean $( \pm \mathrm{SE})$ daily milk intake $(\mathrm{A})$, daily total visits to the milk feeder $(\mathrm{B})$, and duration of visits to the milk feeder $(\mathrm{C})$ of sick and healthy (control, CTRL) calves fed either high or low amounts of milk or milk replacer at each day (d $0=$ day at which illness was first detected). Differences between sick and healthy calves within each milk allowance: ${ }^{*} P<0.05,+P<0.10$. 
$P=0.2$, respectively), but had a reduced duration of the visits to the milk feeder on the day that illness was detected $(P<0.001)$ and on the following $3 \mathrm{~d}$ (Figure $1 \mathrm{C})$.

\section{DISCUSSION}

Illness in calves fed large amounts of milk or milk replacer was associated with reduced milk or milk replacer intake, a reduced number of visits to the milk feeder, and an increased duration of visits to the feeder. These differences were most apparent on the day of diagnosis and the 3 subsequent days. In contrast, sick calves that were fed a low allowance of milk or milk replacer maintained milk intake but showed a reduced duration of visits on the days following illness. Detailed data on feeding behavior such as those automatically collected by automated milk feeders may be useful in detecting illness in group-housed dairy calves, supporting the suggestions of Maatje et al. (1993) and Svensson and Jensen (2007). However, the precise information from automated feeders that is best able to detect sick calves will depend on the level of milk being fed to the calves.

The high feeding motivation of the calves fed low allowances may have limited the effect of illness on milk intake, given that the commercial quantities of milk fed to calves that we used are well below ad libitum intake levels (Jasper and Weary, 2002). Svensson and Jensen (2007) reported that calves fed only $6 \mathrm{~L} / \mathrm{d}$ failed to show a reduction in milk intake but reduced the number of visits to the milk feeder. Similarly, we also found no reduction in milk intake among calves fed low allowances of milk $(4 \mathrm{~L} / \mathrm{d})$. However, we did not find any reduction in the number of visits to the feeder either. The failure to see any change in milk intake in low-allowance calves may have been a result of the limited milk available to them. For instance, despite being sick, the calves provided access to high milk allowances still maintained intakes of approximately 8 $\mathrm{L} / \mathrm{d}$, which was double the milk volume provided to the low-allowance calves. Interestingly, the only change in feeding behavior detected in calves fed low allowances of milk was a decreased duration of visits to the milk feeder. Previously, Borderas et al. (2008) reported that injections of bacterial endotoxin reduced the time calves spent feeding on hay but did not reduce milk intake when the milk allowance was $4 \mathrm{~L} / \mathrm{d}$. Together, these results show that the effects of illness on feeding behavior will vary according to the feeding motivation of the calves.

Reductions in feeding behavior are common responses to illness in animals and are mediated by proinflam- matory cytokines (Millman, 2007; Weary et al., 2009). There is evidence that lower priority behaviors are primarily affected by illness (Weary et al., 2009), and studies on a number of species show that sickness tends to have the greatest effect when the motivation to perform a given behavior is low (Millman, 2007). This study supports that suggestion by showing that increased feeding motivation caused by a low allowance of milk will reduce the effect of illness on feeding behavior. The type of illness could affect which behaviors are affected by illness, but we had too few animals to be able to examine the effect of different illnesses. We strongly encourage future work in this area.

Similar to the results reported by Maatje et al. (1993), milk intake was the variable most responsive to changes in health status for high-allowance milk-fed calves. Daily frequency of visits to the milk feeder also decreased in sick calves fed high allowances of milk and this corresponds to the observed decrease in milk intake. The average duration of the visits to the milk feeder was greater in sick calves fed high allowances of milk than in their healthy matched pairs, which could also be an indicator of illness. Sick calves visit the milk feeder less frequently and it takes them more time to consume a smaller meal compared with healthy calves. Maatje et al. (1993) reported that a decreased drinking rate (which corresponds to a longer duration of the visit) was a reliable indicator of disease.

It is very unlikely that the effects were caused by the veterinary treatment of the calves. Animals showing mild gastrointestinal illness were treated only with an electrolyte solution and kaolin-pectate at therapeutic doses, which should not affect feed intake (Merck, 2006). Moreover, the removal of treated animals did not change the results. Thus, we are confident that the observed behavioral changes were in response to illness and not to the treatment.

Although other studies have reported changes in feeding behavior preceding the onset of disease (Svensson and Jensen, 2007; Lukas et al., 2008) we did not find any changes in the days before the detection of illness. However, this failure to observe any changes in feeding behavior before illness may have been a consequence of the lack of severity of the disease. No calves died and calves responded quickly to treatment (no differences were found in any variable between sick and healthy calves after d 4, indicating that the calves were likely suffering from only mild forms of disease). Furthermore, almost all of the daily health checks were performed by a veterinarian and were likely more rigorous than would normally be used on commercial dairy farms. This likely resulted in more opportune medical treatment that prevented the aggravation of their condition. 


\section{CONCLUSIONS}

Milk feeding allowance clearly affected which aspects of milk feeding behavior changed in relation to sickness and thus must be taken into consideration when using changes in feeding behavior for identifying sick preweaned calves. Sick calves fed high allowances of milk decreased milk intake and total visits to the milk feeder and increased duration of each visit compared with healthy calves with the same feeding allowance. Sick calves fed low allowances of milk only decreased duration of each visit compared with healthy low-fed calves.

\section{ACKNOWLEDGMENTS}

The authors acknowledge I. Blanchet, M. St.-Louis, K. Carter, M. Robertson, B. Sweeney, and the staff at Agriculture and Agri-Food Canada in Lennoxville and Agassiz, as well as N. Dinn and the staff of the UBC Dairy Research and Education Centre in Agassiz for their support. We thank D. Weary (UBC Animal Welfare Program) for useful discussions. F. Borderas thanks Unifeed Ltd., Division of Agricore United, for a generous student fellowship. Funding was provided by a Discovery grant to A. M. de Passillé from the Natural Sciences and Engineering Research Council of Canada.

\section{REFERENCES}

Bøe, K. E., and G. Færevik. 2003. Grouping and social preferences in calves, heifers and cows. Appl. Anim. Behav. Sci. 80:175-190.

Borderas, T. F., A. M. de Passillé, and J. Rushen. 2007. Feeding behavior and weight gain of calves fed low or high quantities of milk using an automated feeding system. J. Dairy Sci. 90(Suppl. 1):95. (Abstr.)

Borderas, T. F., A. M. B. de Passillé, and J. Rushen. 2008. Behavior of dairy calves following a low dose of bacterial endotoxin. J. Anim. Sci. 86:2920-2927.

Borderas, T. F., J. Rushen, and A. M. de Passillé. 2006. Feeding behaviour and response to weaning of calves fed limited or ad libitum milk using an automated feeding system. Page 39 in Proc. 40th Congress Int. Soc. Applied Ethology. Bristol, UK.
Hepola, H. 2003. Milk feeding systems for dairy calves in groups: Effects on feed intake, growth and health. Appl. Anim. Behav. Sci. 80:233-243.

Huzzey, J. M., D. M. Veira, D. M. Weary, and M. A. G. von Keyserlingk. 2007. Prepartum behavior and dry matter intake identify dairy cows at risk for metritis. J. Dairy Sci. 90:3220-3233.

Jasper, J., and D. M. Weary. 2002. Effects of ad libitum milk intake on dairy calves. J. Dairy Sci. 85:3054-3058.

Johnson, R. W. 2002. The concept of sickness behavior: A brief chronological account of four key discoveries. Vet. Immunol. Immunopathol. 87:443-450.

Kung, L. Jr., S. Demarco, L. N. Siebenson, E. Joyner, G. F. W. Haenlein, and R. M. Morris. 1997. An evaluation of two management systems for rearing calves fed milk replacer. J. Dairy Sci. 80:2529-2533.

Lukas, J. M., J. K. Reneau, and J. G. Linn. 2008. Water intake and dry matter intake changes as a feeding management tool and indicator of health and estrus in dairy cows. J. Dairy Sci. 91:3385-3394.

Maatje, K., J. Verhoeff, W. D. Kremer, A. L. Cruijsen, and T. S. van den Ingh. 1993. Automated feeding of milk replacer and health control of group-housed veal calves. Vet. Rec. 133:266-270.

Merck. 2006. The Merck Veterinary Manual. 9th ed. Merck and Co. Inc., Rahway, NJ.

Millman, S. T. 2007. Sickness behaviour and its relevance to animal welfare assessment at the group level. Anim. Welf. 16:123-125.

Quimby, W. F., B. F. Sowell, J. G. P. Bowman, M. E. Branine, and M. E. Hubbert. 2001. Application of feeding behaviour to predict morbidity of newly received calves in a commercial feedlot. Can. J. Anim. Sci. 81:315-320.

Sowell, B. F., J. G. P. Bowman, M. E. Branine, and M. E. Hubbert 1998. Radio frequency technology to measure feeding behavior and health of feedlot steers. Appl. Anim. Behav. Sci. 59:277-284.

Svensson, C., and M. B. Jensen. 2007. Short communication: Identification of diseased calves by use of data from automatic milk feeders. J. Dairy Sci. 90:994-997.

Sweeney, B. 2007. The effects of feed restriction on animal welfare: Examining gradual weaning as a strategy to reduce hunger in dairy calves. MSc thesis. Royal (Dick) School of Veterinary Studies, University of Edinburgh, Scotland.

Sweeney, B., J. Rushen, D. M. Weary, and A. M. De Passille. 2008. Optimal weaning strategies for high-milk-fed dairy calves. Page 108 in Proc. 42nd Congr. Int. Soc. Appl. Ethol., Dublin, Ireland.

Urton, G., M. A. G. von Keyserlingk, and D. M. Weary. 2005. Feeding behavior identifies dairy cows at risk for metritis. J. Dairy Sci. 88:2843-2849.

von Keyserlingk, M. A. G., L. Brusius, and D. M. Weary. 2004 Competition for teats and feeding behavior by group-housed dairy calves. J. Dairy Sci. 87:4190-4194.

Weary, D. M., J. M. Huzzey, and M. A. G. von Keyserlingk. 2009. Board-invited review: Using behavior to predict and identify ill health in animals. J. Anim. Sci. 87:770-777. 